\title{
Introduction to the Research Handbook on the World Intellectual Property Organization - 50 years of the World Intellectual Property Organization
}

Anniversaries provide good opportunities to stop and reflect on what has occurred in the past, as well as speculating on what may happen in the future. In the case of the World Intellectual Property Organization (WIPO), a significant anniversary occurred on 26 April 2020, which was 50 years from the date on which the WIPO Convention 1967 came into force and the date on which WIPO officially came into existence. The aim of the present volume is to provide a series of critical perspectives on this first half century of institutional life and to provoke discussion on where WIPO may be heading as it enters its second.

This is by no means a comprehensive account or history of WIPO in the years 1970-2020: this is a huge task that remains to be done by others and there is a mountain of documentation and other material available to be sifted and examined in detail by future historians. Rather, the perspectives offered here are highly individual and are focused on particular aspects of WIPO and its activities, reflecting a variety of personal experiences and interactions with the organization by contributors with extensive expertise in intellectual property law and policy making. Some of the contributors have worked within WIPO at different stages and have known it at close quarters; others, while strictly outsiders, have had a long history of engagement with the organization and its programmes and governance, often on behalf of their respective governments; others again have been closely involved at different times with particular WIPO initiatives and continue to be so. All contributors, however, have had long experience with the particular areas of IP on which they have written, both at the national and international levels, and bring this knowledge and experience to bear in their assessments of WIPO's role and impact in these areas.

Given the opening caveat that this volume does not purport to cover and examine every aspect of WIPO's wide range of programmes and activities during its first 50 years, there is a progression in themes that I hope will engage the reader who wishes to learn more about this fascinating organization. Thus, in Chapter 1, I seek to describe the origins of WIPO and to describe briefly the steps by which it came into existence. In this, I have been joined as co-author by Gillian Davies, who was one of the original 'insiders'. Gillian, who has had a distinguished subsequent career in IP law (with IFPI, the EPO and at the English Bar) served in the United International Bureaux (BIRPI), the predecessor of WIPO, and was closely involved with the negotiations that led ultimately to the adoption of the WIPO Convention at the Stockholm Revision Conference in 1967. As a young lawyer, she worked closely with Georg Bodenhausen and Arpad Bogsch, who successively became the first and 
second Directors General of the new organization. Half a century later, it is hard to believe that the number of staff employed by BIRPI prior to 1970 was not much more than the number of Assistant Directors General and Directors of sections employed in WIPO today in Geneva and elsewhere (with over 1,500 employees). Gillian's personal reflections on these early days enrich this account of the way in which WIPO came into existence.

One of the critical achievements of this early period was the establishment of WIPO as a fully-fledged international organization that, within four years, became a specialized agency of the UN with competence, though not exclusively, with respect to intellectual property matters at the international level. The implications of this status from a broader legal perspective are examined in Chapter 2 by Alison Duxbury, an expert in international organizations. In this important chapter, Alison examines the characteristics of international organizations and how these map on to the organization that we now know as WIPO as a component part of the wider UN system. In light of the distinctive features of WIPO, she considers the role of international organizations, including their legal status and issues of governance, the vexed question of competence and mandate, including the doctrine of implied powers, and the law-making capacity of international organizations generally, and of WIPO specifically.

In Chapter 3, Gillian Davies joins me again to provide an account of the progress of WIPO from 1970 to 2020 . Our aim here is to provide readers with a general overview of the trajectory of the organization during this period, with all its peaks and troughs, as well as giving a snapshot of the wide variety of programmes and initiatives now being pursued by the organization and the treaties for which it is responsible. Inevitably, much of this history has been shaped by the personalities and abilities of individuals, notably the four Directors General who have served to date. As will be seen, the influence of the second - Arpad Bogsch - is felt even today.

Further insights into particular aspects of WIPO's history are provided in Chapter 4 by Mihály Ficsor, who was intimately involved in the area of copyright and related rights at an exciting stage in WIPO's development, culminating in the adoption of the Internet Treaties in 1996. Mihály was also an influential 'outsider' prior to this period, representing Hungary in WIPO meetings at a time when there was a still a 'socialist bloc' of countries within the WIPO membership. Following his retirement from WIPO at the end of 1998, Mihaly has continued to have a close relationship with the organization in a number of capacities, including authorship of several influential WIPO Guides. His insights, both as an insider and as an outsider, are revealing.

In the succeeding chapters, contributors assess WIPO's role in what may be regarded as its 'traditional' areas of concern - substantive and procedural norm formulation in copyright and related rights, patents, trade marks, geographical indications and industrial designs.

In the case of copyright and related rights, as recounted by myself and Tanya Aplin in Chapter 5, the story of the past 50 years is a mixed one. Initially, the situation looked dire, as a gulf between developed and developing countries over the Stockholm Protocol of 1967 emerged, but this was resolved by the more modest 
Appendix adopted in Paris in 1971. Although still in its infancy, WIPO and its senior officials played a significant role in bringing about this resolution, and continued this work through the 1970s and 1980s in the period of 'guided development' in which widespread consultations on copyright issues continued to be conducted (some under the radar, as fears of reviving the conflicts raised by the Stockholm Protocol experience lingered for a long time). This led to the Berne Protocol process in the early 1990s, a somewhat unstructured endeavour which was possibly a reaction to the developments occurring outside WIPO in the area of trade-related IPRs. Post-TRIPs, however, WIPO's work crystallized in a more targeted programme addressing internet issues, and led, within a comparatively short time, to the negotiation and completion of the two Internet Treaties discussed by Mihály Ficsor in the preceding chapter. Following the Internet Treaties, WIPO's treaty achievements have been more uneven. Projects such as a broadcasters' treaty remain unfinished, while a considerable period elapsed before protection of audio-visual performers was achieved in Beijing in 2012. A notable success, however, was the Marrakesh Treaty of 2013 which responded creatively to the needs of readers with a visual disability. Other projects on limitations and exceptions continue to receive extended discussion in the WIPO Standing Committee on Copyright and Related Rights (SCCR), while others, such as art resale royalty rights and theatre directors' rights hover somewhat uncertainly at the bottom of the SCCR's agenda.

Norm formulation in relation to patents likewise presents a mixed picture of failure and success, and is the subject of Chapter 6 by two distinguished US scholars, Rochelle Dreyfuss and Jerome Reichman. After the collapse of the ill-fated attempts to revise the Paris Convention in the early 1980s, proposals for a substantive patent law treaty also fell by the wayside in the next decade. At the level of procedural harmonization, however, success has been much greater, with the adoption of the PCT and subsequent treaty endeavours. The authors therefore argue that the lesson to be learned here is that when a regime governs a single area of law, especially one that is closely tied to health, safety and economic growth, it is not possible to achieve substantive gains without giving due consideration to the interests of all relevant parties. They end more optimistically by asking whether recent developments provide the basis for a renewed attempt to craft a better harmonized normative framework.

Trade marks, discussed by Graeme Dinwoodie and Annette Kur in Chapter 7, present a different picture again. The body of international trade mark law has grown considerably since the 1883 text of the Paris Convention, and has developed into a complex web of procedural and substantive stipulations. This has created an efficient system for the international registration of marks, with more detailed international rules about such matters as eligibility for protection, scope and limitations of the rights conferred, conditions for rejecting or invalidating trade mark rights in the case of non-use, limits on encumbering use, and the conditions on which assignments and licences may be granted. By contrast, limited attention has been paid at the international level to what is usually referred to as 'absolute grounds' for refusal, that is grounds for denying trade mark registrations because the registration sought would interfere with a public interest (as opposed to conflict with an earlier private right). So 
far as any international norm on this subject is concerned, it is to be found in Article 6quinquies(B) of the Paris Convention, but the interpretation and application of this provision - crafted in an era when trade marks were usually word marks, or at most signs containing pictorial elements - does not address what today is referred to as 'nonconventional' or 'nontraditional' marks. Article 6quinquies(B)(iii) of the Paris Convention also permits rejection of marks that inter alia are contrary to morality or public order. The relationship between those concepts and trade mark registration is not clear and courts in several countries recently have had to grapple with national provisions reflecting this ground for refusal. However, there has been no meaningful consideration of this issue at the international level, and the authors argue that this opens a field for future WIPO action. Rather than promulgating new treaty revisions or instruments addressing substantive provisions - a task that has proved notoriously difficult since 1967 - Graeme and Annette argue that it would be better for WIPO to pursue the path already successfully explored around the turn of the century, when 'Joint Recommendations' were elaborated in the framework of the WIPO Standing Committee on Trademarks, Designs and Geographical Indications (SCT) on such matters as famous marks and online uses of signs. In other words, the authors advocate the adoption of 'soft law' options that will promote national harmonization over time without the accompanying traumas of prolonged treaty negotiations.

In the case of geographical indications, Dev Gangjee in Chapter 8 argues that, building on developments at the national level, notably in Europe, WIPO has played a key role in creating broader international awareness of these as a subject of IP protection. This has implications for both developed and developing countries, as well as for existing regimes such as trade marks. WIPO's activities in this area comprise long-running programmes of symposia and conferences, the provision of technical assistance, and the development of extensive informational resources. In particular, WIPO is responsible for the operation of the Lisbon system for the international registration and protection of appellations of origin, although the recent expansion of this system, culminating in the Geneva Act of 2015, exposed fundamental tensions relating to who has a say in multilateral law-making and the extent to which specialized interests can be cross-subsidized by WIPO's general membership. Disputes relating to the reform of Lisbon go to the heart of WIPO's constitutional framework; nonetheless, WIPO's role in articulating the basis for, and the content of, such protection at the national and international levels has been notable.

In the case of industrial designs and models, Antoon Quaedvlieg in Chapter 9 argues that WIPO's history in developing an international system of protection has two sides: in procedural terms, this has worked well; in substantive terms, little has been achieved, and diverging national positions in the early history of design right have, for too long, dominated the discussions at the international level. Antoon therefore begins by examining the national 'prehistories' preceding the Berne and Paris Conventions, and then tracks the international development of copyright and design law under these conventions. He concludes by addressing a question that finds its source in the present structure of the international treaties, under which it is possible that a period of protection as a registered design may be followed by a period of con- 
tinued protection as an unregistered right by copyright, and considers how this may be explained. This remains a major substantive legal and policy challenge for WIPO.

Turning from the more discrete legal issues raised by WIPO's traditional norm formulation activities, the following chapters (Chapters 10-15) address matters of a more wide-ranging and cross-cutting character: WIPO and development issues (including the Development Agenda); technical assistance and education programmes; trade-related intellectual property rights and relations with the World Trade Organization (the WTO or the 'new kid on the block'); the work of the WIPO Intergovernmental Committee on Intellectual Property and Genetic Resources, Traditional Knowledge and Folklore (the IGC); WIPO's role in dispute resolution; and WIPO's evolving role in relation to data collection and economic policy analysis.

As to the first of these topics, Michael Blakeney in Chapter 10 examines the history of WIPO's work in relation to developing countries, drawing on his own personal experience working in WIPO on these matters in the $1980 \mathrm{~s}$, and relates some of the legal and political issues that arose here. He then describes the developments that led to the adoption of the Development Agenda in 2007, and analyses the various initiatives contained in this. His conclusion is that the jury is still out on the effectiveness of this project.

In Chapter 11, Raquel Xalabarder addresses a related topic, namely WIPO's role with respect to technical assistance and capacity building (education and training). She notes that this began with legal technical assistance as early as 1967, and then broadened out into education, training and capacity building at large. More recently, this has led to the development of several public-private partnerships. Raquel describes and analyses the extent of these activities, including a consideration of how they play into the Development Agenda and other work in the trade mark, copyright and traditional knowledge areas. She also identifies potential areas of difficulty that arise in carrying out these programmes, particularly in the case of public-private partnerships.

In Chapter 12, Daniel Gervais considers the relationship between WIPO and the new phenomenon of trade-related intellectual property rights that came out of the Uruguay Round of GATT and the establishment of the WTO. Written from the perspective of someone with experience in both WIPO and WTO at the relevant times, Daniel examines the present relationship between the two organizations, identifying it as one where WIPO has maintained a comparative advantage over the WTO in terms of its technical expertise and resources. The relationship has not always been easy, particularly in the early days before the conclusion of the TRIPS Agreement. Overall, however, there is a healthy balance between the two organizations, each having its own role in relation to intellectual property matters.

While genetic resources, traditional knowledge and traditional cultural expressions differ from the objects of pre-existing, 'classical' intellectual property rights in many fundamental aspects, they have become a central part of WIPO's current activities through the work of the IGC which was established in 2001. Prior to this, WIPO's concerns had only been with what was called 'expressions of folklore'. In Chapter 13, Silke von Lewinski, who has had long experience as both a German representa- 
tive and as an observer at IGC and related meetings, discusses the particularities of these new subject matters and prospective right holders - in particular, indigenous communities - and how WIPO has responded to the related challenges so far, including procedural challenges as regards indigenous participation. While attempts at developing new international norms in the form of treaty language continue to be difficult, when faced with lack of experience at national level and the diverging positions of member states, Silke highlights the usefulness of WIPO's background information gathering activities and practical work as well as the legislative drafting process that has been occurring within the IGC. As long as the political will is insufficient for international norm making, she suggests that steady legislative advice by WIPO at the national level could finally lead to greater experience on the ground and thus ultimately to a basis for agreement on which more general international norms might be established.

One particular area in which WIPO has moved outside its more traditional sphere of activity has been in relation to dispute resolution services provided through its Arbitration and Mediation Centre, established in 1993. This development is explored and evaluated by Andrew Christie in Chapter 14. He begins by describing the genesis for the provision of such services, and the type of services provided and then considers in detail the most important (as judged by impact) of these - the resolution of domain name disputes under the Uniform Dispute Resolution Policy (the UDRP) and its derivatives. WIPO's critical role in the design and the implementation of the UDRP is explained, and the UDRP's significant features and impact are discussed. Andrew then undertakes a critical assessment of the UDRP in operation - and, in particular, its fairness - and concludes that the success of the UDRP has been a major achievement on the part of WIPO.

From their inception, the united international offices (BIRPI) collected and published IP data and statistics - filings, registrations and the like. This activity has continued apace under WIPO, but now assumes a vastly different character from 1970, let alone 1885 (the date of establishment of the International Office under the Paris Convention). In Chapter 15, David Lindsay describes and analyses the evolution of WIPO's roles in the collation and publication of these materials, as well as in relation to the economic analysis of IP. He then examines the functions currently performed by WIPO's Economic and Statistics Division, concluding that recent revolutions in data collection, processing and analysis are transforming WIPO, so that it is becoming a predominantly data-driven organization. As such, it is now an integral part of what might be termed the 'datafication' of the global IP system.

In the next four chapters, matters of a more institutional and operational kind are addressed, together with some commentary on future challenges for WIPO at the organizational level.

Ian Heath, a former Director General of IP Australia, represented the Australian Government in the tumultuous first decade of the twenty-first century during the Kamal Idris period and into the first years of the term of Francis Gurry. In Chapter 16, Ian addresses issues of governance and finance within WIPO. Initially, the organization was in a relatively precarious financial position, heavily dependent upon 
member states' contributions. However, this position has changed radically with the 'rivers of gold' received through PCT and Madrid Protocol revenues, making it an almost entirely self-financing body, a rarity in the UN system. Ian traces the way in which this has occurred and considers its wider implications with respect to issues of governance and accountability. He also examines the constitutional structure of WIPO and its relationship to the various 'sovereign' unions that come within its organizational umbrella, as exemplified by recent controversies in relation to the Lisbon Union. He ends by asking, how financially secure and soundly constructed is the financial and governance edifice that is WIPO today?

In Chapter 17, Susy Frankel considers another important aspect of WIPO activities, namely its continuing role in treaty making and interpretation. She examines the rules relating to the interpretation of treaties, as embodied in the Vienna Convention on the Law of Treaties (VCLT), and argues that there is little indication that WIPO applies these rules in the drafting and application of its own treaties, and that this can have unexpected effects as more and more other international organizations become involved in the international intellectual property system. In particular, she highlights the use of preambles as part of the 'context' in the interpretation of treaty provisions, and provides a critique of the way in which WIPO has evolved the use of 'agreed statements' in recent years. She argues that WIPO should, in the future, align its treaty drafting practices more closely with the VCLT rules so as to achieve greater concordance with the way in which these rules are applied by other international actors.

In Chapter 18, in an account that cuts across many of the topics considered in preceding chapters, Peter Yu considers WIPO and its relations with emerging economies. Since its establishment in April 1970, the North-South divide has dominated debates within WIPO concerning the shape and scope of international intellectual property regimes. Notwithstanding these debates, the past two decades have seen the arrival of emerging economies, such as Brazil, China and India, and this has revealed diverging views on the role of IP law and policy making at the international level. Peter provides an illuminating account of the changing international landscape, and then explores the emerging economies' impacts on WIPO and its activities. He concludes by offering insights into the Organization's future.

In Chapter 19, Tony Taubman, a former WIPO officer and now a senior WTO official, provides a fascinating account of the developing role of observers within WIPO and its meetings, noting that there is a history of such involvement here that can be traced back to the introduction of the right of priority into the Paris Convention. He considers the evolving role and influence of observers within WIPO, the progressively diversifying character of such persons and the bodies they represent, and the varied policy perspectives they advocate and advance. Finally, he reflects on the implications of these trends for the international governance of IP law and policy and the wider political context of IP, focusing on the influence of civil society actors on public policy issues and the inclusion of indigenous communities in the work of the IGC.

While speculation about the future of WIPO, and what it might or should be doing in the future, is to be found in each of the preceding chapters, Rebecca Giblin, Jane 
Ginsburg, Kim Weatherall and Jukka Liedes confront this subject directly in the penultimate chapter (Chapter 20). This provocative contribution examines the gaps in WIPO's present programmes and discusses what the organization might do to contribute more responsibly and effectively to the international system. The authors identify two particular areas in which this might occur. The first is through creating a more balanced system that enables creativity for all in the field of copyright, given the way in which existing treaties constrain its margin for manoeuvre, and given also how politicized and polarized discussions at WIPO have become. Voluntary and networked systems of recordation of rights and their exploitation provide one way forward that is consistent with the current international conventions and which is now enabled by new information and communications technologies. The second area for consideration is how WIPO can confront the urgent challenges of climate change with the tools that are at its disposal. The first of these authors' proposals for change involves a paradigm shift in thinking about copyright; their second has no lesser an objective than saving the planet from global warming - or, at the very least, maximizing what WIPO can do in relation to this within its existing resources and technical expertise. Both proposals would require WIPO to rethink its overall mission, particularly in relation to the deployment of its PCT and Madrid surpluses, and to adopt a wider and more integrated role in the overall UN system. This is a siren call for action that, while idealistic in one sense, is highly practical in another.

Finally, in Chapter 21, I provide, by way of concluding commentary, a summary and assessment of the different perspectives offered by contributors in the preceding chapters. While the 'mission' of WIPO over the past 50 years has evolved far beyond what may have been conceived in 1970, in terms of resources, personnel and finances, it is now a critical component of the wider UN system. In tangible terms, it has been a 'rags to riches' success story, with ups and downs along the way, a gallery of notable personalities (not just at the Director General level), institutional contests over 'turf', and an ever-increasing engagement with wider social, economic and cultural issues. It is a fascinating and multifaceted story. At the same time, like many other international organizations, it is under pressure from many directions, some benign and others less so, including attacks on the very notion of multilateralism that has underpinned the organization from its inception. Debates over the mandate of the organization and its role can only be expected to intensify - indeed, there are those who would argue for a more radical alignment than is suggested in the preceding chapters. How these conflicting pressures are to be reconciled and resolved in the next 50 years is a major challenge for the new leadership that will take office late in 2020. All that can safely be predicted is that, 50 years from now, whatever is then called WIPO will be unrecognizable from the perspective of 2020. I hope there is enough in this volume to whet the appetite of readers who may previously have known little about WIPO and to encourage them to find out more and engage more fully with the organization. For 'old hands', I hope there are sufficient new insights and perspectives to intrigue, entertain and inform.

In closing, I must record my profound gratitude to each of the contributors to this volume for their readiness to participate in this project, and for the insights, advice 
and guidance they have provided along the way (it has been an educative and iterative process throughout); to the Intellectual Property Research Institute of Australia (IPRIA) of the University of Melbourne and, in particular to my colleague Megan Richardson, the then IPRIA Director, for providing critical support in the editing phase of the project; to Georgina Dimopoulos in Melbourne and Rose Campbell in London for their meticulous copy editing; and, finally, to Luke Adams, Laura Mann, Saffron Watts and Kaitlin Gray of Edward Elgar for their encouragement and efficiency in shepherding it so seamlessly through the various stages from inception to completion.

Sam Ricketson

Melbourne

15 February 2020 
Sam Ricketson - 9781788977678 Downloaded from PubFactory at 04/26/2023 11:25:24AM via free access 